\title{
A personal digital assistant application (MobilDent) for dental fieldwork data collection, information management and database handling
}
IN BRIEF
- Describes the development and application of a novel PDA concept in dentistry, with a unique back-office system and dental health epidemiology database.
- The system interfaces are easy to translate to different languages and applications.
- The concept has unique applicability in areas with few dentists or dental hygienists, since large populations may be screened by relatively few dental professionals.

\author{
M. Forsell, ${ }^{1}$ M. Häggström, ${ }_{1}^{2}$ O. Johansson ${ }^{3}$ and P. Sjögren ${ }^{4}$
}

\begin{abstract}
Objective To develop a personal digital assistant (PDA) application for oral health assessment fieldwork, including backoffice and database systems (MobilDent). Design System design, construction and implementation of PDA, back-office and database systems. Methods System requirements for MobilDent were collected, analysed and translated into system functions. User interfaces were implemented and system architecture was outlined. MobilDent was based on a platform with .NET (Microsoft) components, using an SOL Server 2005 (Microsoft) for data storage with Windows Mobile (Microsoft) operating system. The PDA devices were Dell Axim. Results System functions and user interfaces were specified for MobilDent. User interfaces for PDA, back-office and database systems were based on .NET programming. The PDA user interface was based on Windows suitable to a PDA display, whereas the back-office interface was designed for a normal-sized computer screen. A synchronisation module (MS Active Sync, Microsoft) was used to enable download of field data from PDA to the database. Conclusions MobilDent is a feasible application for oral health assessment fieldwork, and the oral health assessment database may prove a valuable source for care planning, educational and research purposes. Further development of the MobilDent system will include wireless connectivity with download-on-demand technology.
\end{abstract}

\section{INTRODUCTION}

The use of handheld computers, or personal digital assistants (PDAs), has found widespread applications in healthcare settings during the past decade. ${ }^{1,2}$ PDA systems allow flexibility and mobility in patient data collection and information retrieval of clinical test results at the bedside. ${ }^{2,3}$ PDA systems have been developed and implemented for different areas related to medical and nursing situations. ${ }^{1-3}$ However, PDA applications for dental practice are scarce. ${ }^{4-8}$

In the current Swedish public dental health insurance system, introduced in January $1999,,^{9,10}$ it was decided as

\footnotetext{
'Dentist, ${ }^{2}$ Systems Engineer, Oral Care AB, Box 2075, 10312 Stockholm, Sweden; ${ }^{3}$ Associate Professor, The Experimental Dermatology Unit, Department of Neuroscience, Karolinska Institute, 17177 Stockholm, Sweden; ${ }^{4}$ Senior dentist, PhD, Oral Care AB, Drottninggatan 13, 41114 Göteborg, Sweden

${ }^{*}$ Correspondence to: Dr Petteri Sjögren

Email: petteri.sjogren@oralcare.se
}

\section{Online article number E17}

Refereed Paper - accepted 28 July 2008

DOI: $10.1038 /$ sj.bdj.2008.873

${ }^{\circledR}$ British Dental Journal 2008; 205: E17 a common public health strategy that community-dwelling elderly and handicapped patients, as well as certain other prioritised groups of the Swedish population, would receive a free annual oral health assessment. Thus, free annual oral health assessments are currently (year 2008) offered to, for example, all elderly nursing home residents, by visiting the entitled individuals at their homes. Therefore, regional private entrepreneurs as well as the public dental service organisations have procured the contracts for oral health assessments from the various county councils in Sweden..$^{9,10}$

Within the contracts for oral health assessments, patients' oral health data need to be recorded and translated into oral hygiene recommendations to ensure that the entitled individuals receive adequately provided oral care on a daily basis. ${ }^{9,10}$ Another, equally important objective is to recommend professional dental treatment (ie dentist or dental hygienist) when needed.

Previously, when conducting the oral health assessments, only hand-written or printed address lists, epidemiological data storage sheets, management and invoice distribution documents, oral health status registration sheets, oral hygiene and dental treatment recommendation sheets, and patient data records have been available. Thus, the administration involved has been timeand effort-consuming. In addition, handwritten documents increase the risk of medical errors and mistakes in dental health data registration during the oral health assessments. ${ }^{1}$ Therefore, in order to rationalise and secure the quality of the collected oral health assessment data, and to shorten the time-span from diagnosis to provided treatment, there was an urgent need to develop a PDA system for this dental fieldwork. To our knowledge there are no available PDA systems designed for patient data collection in dental fieldwork. Therefore, this study was initiated with the objective to develop a PDA-based system (MobilDent) suitable for oral health assessment fieldwork, including back-office administration and database systems. 


\section{MATERIAL AND METHODS}

\section{System requirements}

The design objective behind MobilDent was to develop and implement a mobile PDA system that would facilitate the fieldwork and the administrative handling of data before and after the oral health assessments. In meetings with experienced administrators and fieldwork personnel at Oral Care AB (Stockholm, Sweden), the system requirements for MobilDent were collected, using a modified Question Option Criteria (QOC) design rationale. ${ }^{11}$ Briefly, instead of a questionnaire survey, the discussions were kept open to derive the options and criteria (ie advantages and disadvantages for different system options). ${ }^{11}$ The system requirements drawn from the design objective were analysed and translated to system functions. Based on the results from these analyses, user interfaces to fieldwork data collection and back-office administration were implemented. System architecture was outlined based on fieldwork experiences and administrative requirements for the back-office and database systems.

\section{System description}

The PDA devices were Dell Axim with the Windows Mobile (Microsoft) system installed. MobilDent was based on a platform with .NET (Microsoft) components, using an SQL Server 2005 (Microsoft) for data storage, with Windows Server 2003 operating system. The MobilDent server application was made responsible for retrieving data from the field data repository, data translation and formatting for database storage and administrative purposes. For secure data storage the MobilDent database runs on an SQL server with redundant drives in a secure server hotel. A full database backup is carried out daily and the tapes stored at a separate physical location.

\section{RESULTS}

\section{System requirements}

The system requirements were specified from data collected at meetings with experienced administrators and field workers (Table 1). The requirements were used to specify system functions and

Table 1 System requirements translated from design objective meetings with dental field workers and office administrators

\begin{tabular}{l|l|l}
\hline Requirement & Field personnel & Office personnel \\
\hline Correct information about fieldwork location & $\mathrm{x}$ & $\mathrm{x}$ \\
\hline Correct patient data & $\mathrm{x}$ & $\mathrm{x}$ \\
\hline Database for budget and research purposes & & $\mathrm{x}$ \\
\hline Enable statistical analyses of field data & & $\mathrm{x}$ \\
\hline Facilitate billing procedures & & $\mathrm{x}$ \\
\hline More efficient fieldwork logistics & $\mathrm{x}$ & $\mathrm{x}$ \\
\hline More efficient resource planning & & $\mathrm{x}$ \\
\hline More quality time with the patient & $\mathrm{x}$ & \\
\hline Quality assurance of collected data & & $\mathrm{x}$ \\
\hline Reduce the administrative time for field personnel & $\mathrm{x}$ & \\
\hline Shorten the waiting time for patients and personnel & $\mathrm{x}$ &
\end{tabular}

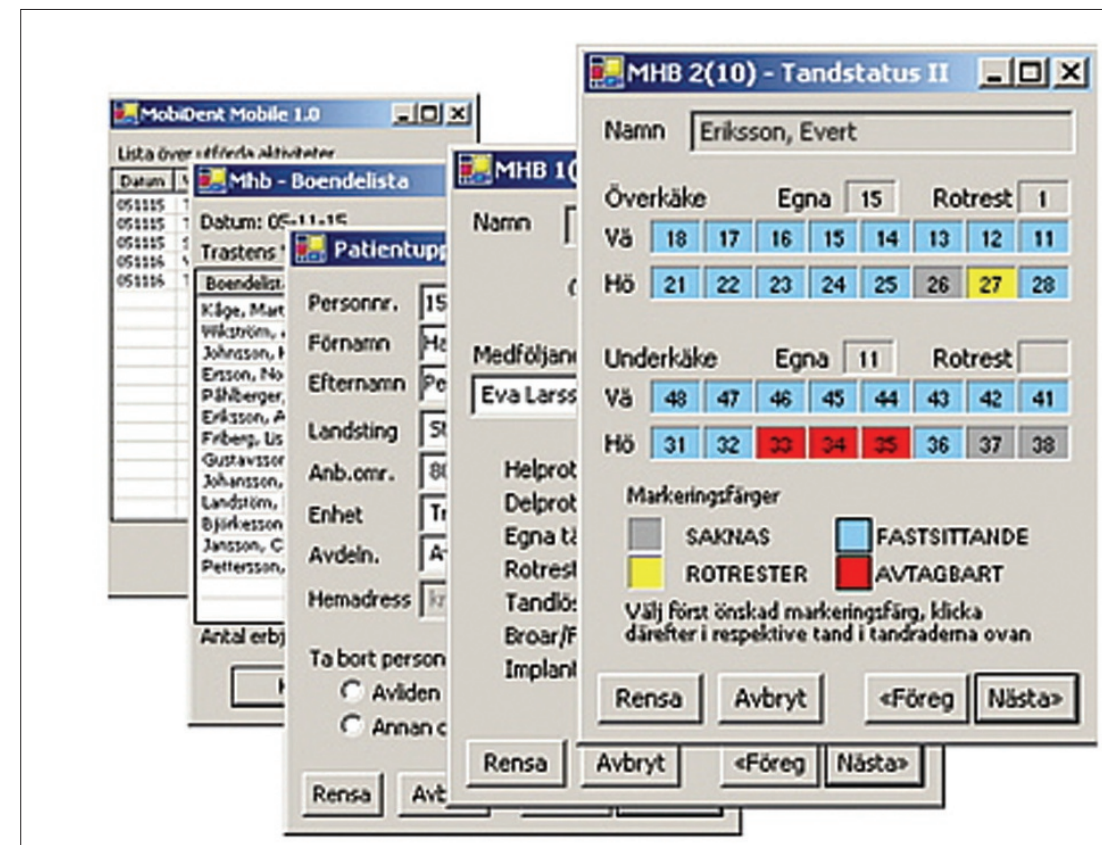

Fig. 1 The PDA user interface based on several user-friendly data entry screens suitable for a PDA display

user interfaces for the MobilDent PDA, and for the back-office administration and database systems.

The user interfaces for MobilDent PDA and for the back-office system were based on .NET programming, and the Windows Mobile (Microsoft) operating system was used for program and database handling. The PDA user interface was based on several user-friendly data entry screens suitable to a PDA display, for efficient data collection and fieldwork administration (Fig. 1).

The MobilDent back-office interface was designed to enable administration and database handling on different displays, suitable for administration on a normal-sized computer screen (Fig. 2).

A synchronisation module using MS Active Sync (Microsoft) was used to enable download of field data from the MobilDent PDA to the MobilDent backoffice and database systems. The complete system architecture outlined for MobilDent is displayed in Figure 3.

\section{Field work implementation}

The use of MobilDent for oral health assessment fieldwork was initiated in January 2006, and has thus far (March 


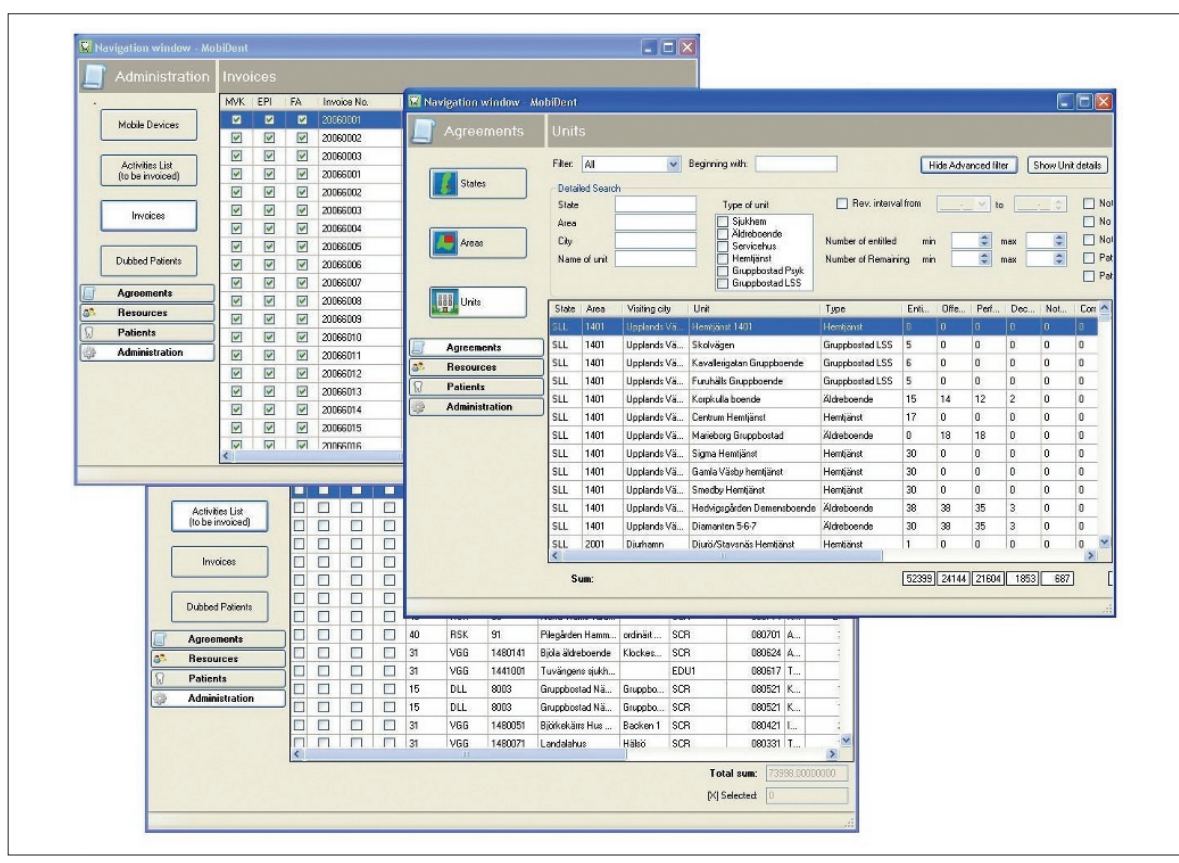

Fig. 2 The MobilDent back-office interface suitable for administration on a normal-sized computer screen

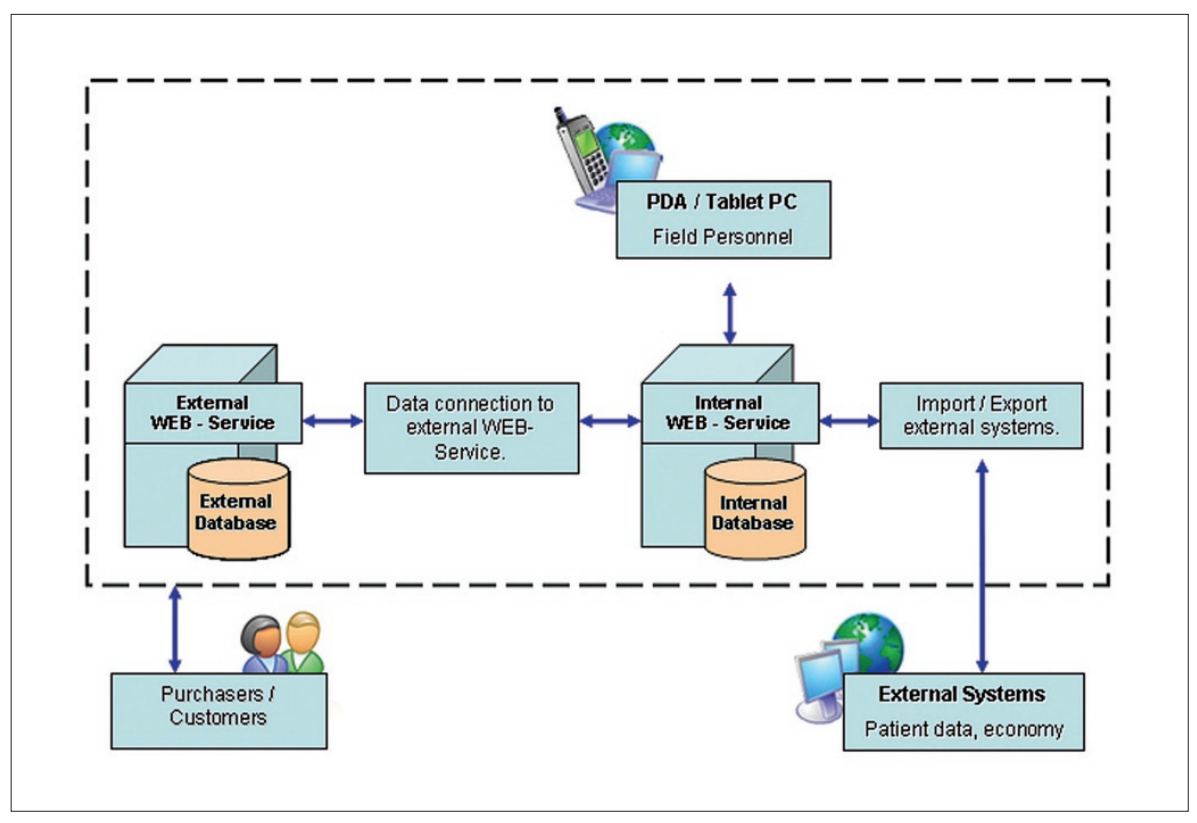

Fig. 3 Outline of the complete system architecture for the MobilDent system

2008) been used for $>40,000$ oral health assessments.

The oral health data collected during the fieldwork were mainly related to different aspects of oral health, including clinical data on: oral health status (eg dental implants, fixed and removable prosthetics, oral mucosa, teeth present); subjective status (eg chewing ability, discomfort or pain, mouth dryness); given recommendations (eg dental hygiene measures, need for help with daily oral hygiene, oral hygiene products); present dental treatment need (eg dental treatment needed due to dental caries or gingivitis); and present dental treatment demand (ie the patient's wish to receive dental treatment).

The field personnel quickly adapted to the use of the MobilDent PDA and found it convenient to work with on a daily basis. Both the field personnel and the administrative personnel using the back-office system considered the shift from hand-written sheets to digital handling of data most helpful in their daily work. The impression was that MobilDent had an easy-to-navigate interface, with a convenient schedule for booking of personnel and resources. The interface also facilitated retrieval of oral health reports and invoices for purchasers.

\section{DISCUSSION}

The aim of this study was to develop and implement a PDA system for oral health assessment fieldwork, including backoffice and database systems for administrative purposes.

The currently presented MobilDent PDA and back-office system was developed as a response to a demand for an efficient administration system in a growing fieldwork organisation conducting oral health assessments. During the system design, it was considered important that the field workers would be able to collect the required patient data conveniently, and that the administration before and after the fieldwork would be rationalised and all data secured. Therefore, system requirements for MobilDent were collected in discussions and interviews with experienced administrators and field work personnel. A highly prioritised design objective was to create an easy-to-use interface, as this had been previously suggested as the most important factor for successful mobile care systems. ${ }^{3}$

The system requirements elicited from the design meetings were analysed and translated to system functions, and the outlined system architecture should be viewed as a trade-off between the requirements of a state-of-art data collection system and a pragmatic tool for the field workers in the oral health assessment situation. To be accepted in the fieldwork situation, it was considered important that the design of the program and the interface would meet the expectations and demands of the dental professionals.

Similarly, based on the results from these analyses, user interfaces to the back-office administration were implemented. The presently used method for collecting system requirements may be regarded as a pragmatic modification of the Question Option Criteria (QOC) design rationale. ${ }^{11}$ However, instead of a questionnaire survey, the questions were kept open in the discussions during the meetings with administrators and field workers, and the answers were analysed and translated into options and criteria 
(ie perceived advantages and disadvantages for different system options). ${ }^{11}$

The use of information technology is increasing in importance in clinical settings and has been proposed to improve medical records documentation as well as patient care. ${ }^{1,10}$ The MobilDent system has been implemented in oral health assessment fieldwork since the beginning of 2006, and is currently (2008) used in four different county councils or regions in Sweden, in three of which the largest Swedish urban areas are located. Experiences from fieldwork with the MobilDent PDA system indicate that, although initial adaptation problems were noticed among the dental field workers, the current MobilDent PDA version is generally considered a feasible, user-friendly system, which is almost self-instructing.

The MobilDent back-office administration system has rationalised the administration routines between purchasers and providers by eliminating an estimated 70,000 sheets of office paper that previously had to be hand-written annually. For nursing homes, the MobilDent back-office administration system has provided clear and concise colour print-outs of oral hygiene and dental treatment recommendation sheets. Furthermore, the time between the oral health assessments and provided dental care is considered to be shorter, and the risk of missing patients in need of dental care has diminished.

The MobilDent database today contains $>40,000$ oral health assessment records and is considered a valuable data source, which in a community dentistry context may prove useful for care planning, educational purposes, epidemiological research and resource allocation. In addition, the collected data may be used for prognostic purposes when the need for dental clinicians within a certain geographical area is planned in the future. At an individual level, the care data may be utilised by the caregivers to provide the caretakers with the required level of dental hygiene, as well as correct attendance from dental professionals.

As previously suggested, future development of health informatics is likely to incorporate dental electronic health records with medical records to form integrated care pathways. ${ }^{12}$ Such care pathways need to include adequate oral hygiene and preventive interventions, as well as dental treatment. The integration of dental professionals with nursing and medical care is increasingly important, especially for elderly and medically compromised individuals, since scientific evidence indicates a strong relationship between oral infections and general health complications. ${ }^{13-15}$ Therefore, future development of MobilDent and other computer-based support tools ${ }^{12}$ will include incorporation of continuously updated online evidence-based medicine tools, leading to patient-focused, efficient dental care. This will also provide advantages in dental hygiene education for nursing personnel. In Sweden, as well as in other developed countries, an increasing proportion of dependent elderly have fixed appliances (eg crowns, bridges, dental implants) which pose heavier demands on the dental hygiene skills of nursing home staff. ${ }^{16,17}$ Thus, planning of adequate dental hygiene education for nursing home staff, based on treatment need data, is crucial.

The MobilDent system is currently based on a PDA for fieldwork, a backoffice system and a database. A synchronisation module in the office transfers the PDA data to the back-office and database systems. Further development of MobilDent will include wireless connectivity to the database, for example, by using download-on-demand technology, instead of downloading data periodically via a synchronisation process. ${ }^{2}$ The PDA devices will also be exchanged for new, more powerful units. In the future, the MobilDent system could easily be modified for applications outside dental fieldwork, for example for bedside patient data registration at nursing homes or hospitals.

\section{CONCLUSIONS}

The MobilDent PDA is a feasible application for oral health assessment fieldwork, together with the MobilDent back-office administration and database systems. The MobilDent oral health database is a valuable source for care planning, educational and research purposes. Further development of the MobilDent system will include wireless connectivity to the database with download-ondemand technology.

Marianne Forsell, Michael Häggström and Petteri Sjögren were supported by Oral Care $A B$, Stockholm, Sweden, and Olle Johansson was supported by grants from The Karolinska Institute, The Cancer and Allergy Foundation (Cancer-och Allergifonden) and the Help Foundation (Hjälpfonden). The work of Emma Hallqvist and Laila Norin (Oral Care AB, Stockholm, Sweden) on the requirements for the MobilDent user interfaces, and the work of Matts Tannerfeldt (Oral Care AB, Stockholm, Sweden) on the MobilDent database and back-office systems, is greatly acknowledged. We thank Matthew Renard (Oral Care AB, Stockholm, Sweden) for help with the figures during revision of the manuscript.

1. Wu R C, Straus S E. Evidence for handheld electronic medical records in improving care: a systematic review. BMC Med Inform Decis Mak 2006; 6: 26.

2. Chen ES, Mendonça E A, McKnight LK, Stetson P D, Lei J, Cimino J J. PalmCIS: a wireless handheld application for satisfying clinician information needs. J Am Med Inform Assoc 2004; 11: 19-28.

3. Choi J, Chun J, Lee K et al. MobileNurse: hand-held information system for point of nursing care. Comput Methods Programs Biomed 2004; 74: 245-254.

4. Reynolds P A, Harper J, Dunne S, Cox M, Myint Y K. Portable digital assistants (PDAs) in dentistry: part I. Br Dent J 2007; 202: 409-413.

5. Reynolds PA, Harper J, Dunne S, Cox M, Myint YK Portable digital assistants (PDAs) in dentistry: part II - pilot study of PDA use in the dental clinic. Br Dent J 2007; 202: 477-483.

6. Hirani S, Hodgkins J, Chen S D, Lucas G. Current products and practices: personal digital assistants in orthodontics. J Orthod 2005: 32: 61-68.

7. $\mathrm{Ng} \mathrm{CH}, \mathrm{Ng} \mathrm{CW}$, Soh E, Yeo J F. The PDA and the oral maxillofacial surgeon. Singapore Dent J 2004; 26: 7-9.

8. Taylor M H. Handheld computing in dentistry. Dent Clin North Am 2002; 46: 539-551.

9. Jonsson M. Effekterna av en reform. Svensk Sjukhustandläkartidning 2008; 33: 20-22.

10. Söderpalm Andersen E, Söderfeldt B, Kronström M. Oral health and treatment need among older individuals living in nursing homes in Skaraborg, Västra Götaland, Sweden. Swed Dent J 2006; 30: 109-115.

11. Sjöberg C. Voices in design: argumentation in participatory development. Linköping studies in science and technology, Thesis No. 436. Linköping: Linkoping University, 1994.

12. Reynolds P A, Harper J, Jenner A M, Dunne S. Better informed: an overview of health informatics. Br Dent J 2008; 204: 259-264.

13. Scannapieco FA, Bush R B, Paju S. Associations between periodontal disease and risk for nosocomial bacterial pneumonia and chronic obstructive pulmonary disease. A systematic review. Ann Periodontol 2003; 8: 54-69.

14. El-Solh A A, Pietrantoni C, Okada M, Zambon J, Aquilina A, Berbary E. Colonization of dental plaques: a reservoir of respiratory pathogens for hospital acquired pneumonia in institutionalized elders. Chest 2004; 126: 1575-1582.

15. van Winkelhoff A J, Slots J. Actinobacillus actinomycetemcomitans and Porphyromonas gingivalis in nonoral infections. Periodontol 2000 1999; 20: 122-35.

16. Hugoson A, Koch G, Göthberg C et al. Oral health of individuals aged 3-80 years in Jönköping, Sweden during 30 years (1973-2003). II. Review of clinical and radiographic findings. Swed Dent J 2005; 29: 139-155.

17. Ahacic K, Thorslund M. Changes in dental status and dental care utilization in the Swedish population over three decades: age, period, or cohort effects? Community Dent Oral Epidemiol 2008; 36: 118-127. 